سعاد عبد عباوي جامعة الموصل- - مبل

ليث عبد العليم العناز

كلبة الهندسة

ملخص البحث

جرى التركيز في هذا البحث على تقييم تر اكيز الفلور في مياه الثرب داخل مدينة الموصل

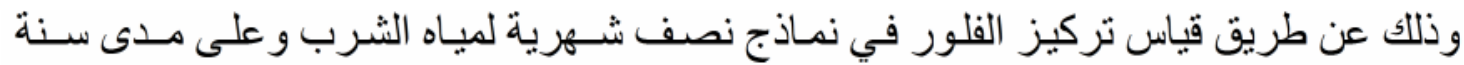

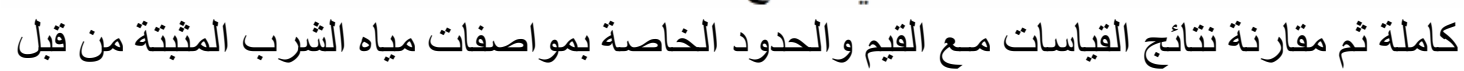

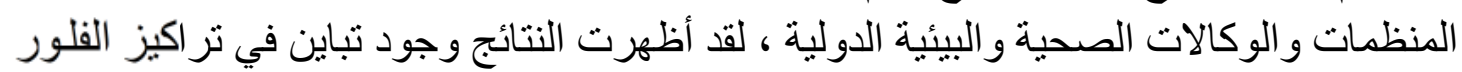

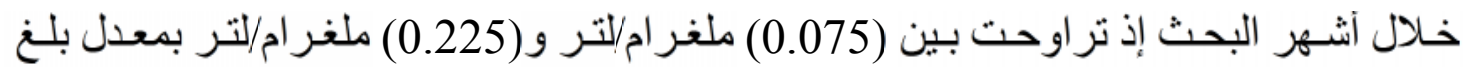

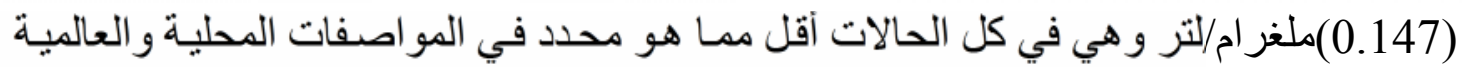

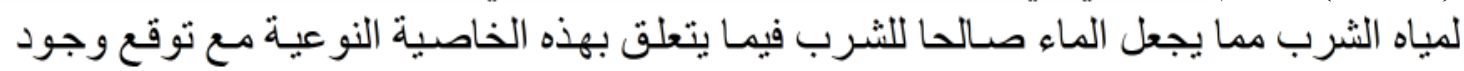

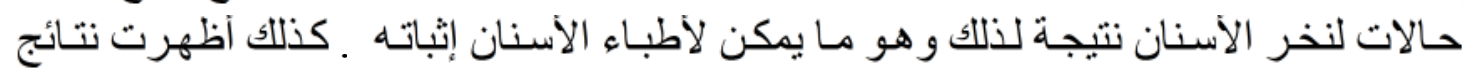

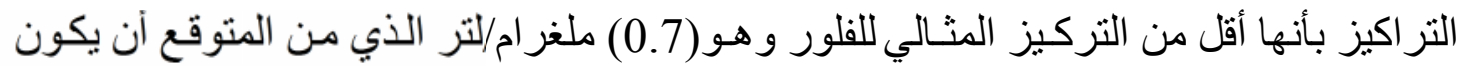

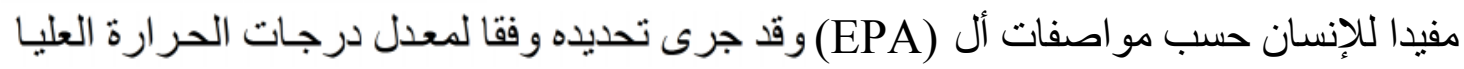

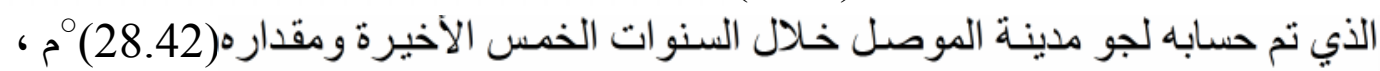

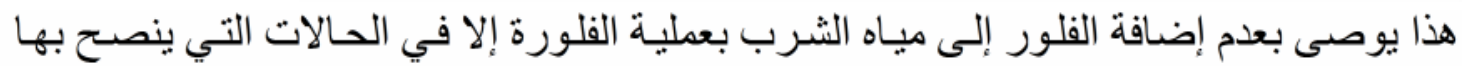

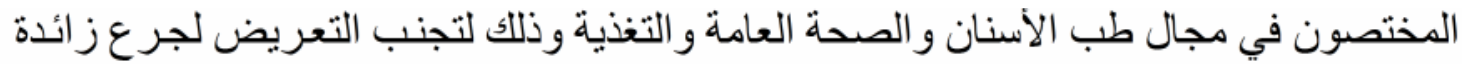

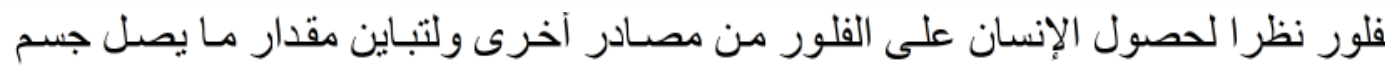

\title{
Evaluation of fluoride concentrations in Mosul city
}

\section{Drinking Water}

Layth A. Al-Annaz
Suaad A. Abawi

University of Mosul - Collage of Engineering 
concentrations . It ranges from $(0.075) \mathrm{mg} / \mathrm{l}$ to $(0.225) \mathrm{mg} / \mathrm{l}$ with an average of $(0.147) \mathrm{mg} / \mathrm{l}$. All samples concentrations are lower than the guide values. Thus the water is suitable for drinking as far as this characteristic concerned, with an expectation that dental caries cases may be appearance .

The results also indicated that all fluoride concentrations in Mosul city drinking water were less than the optimum value which is $(0.7) \mathrm{mg} / \mathrm{l}$, according to EPA. This value was stabilized according to the mean value of maximum daily temperature for the Mosul city (28.42) ${ }^{\circ} \mathrm{C}$ over the last (5) years. However, to avoid consumed excessive dosage of fluoride, the fluoridation should not be practiced unless it is advised by the specialists in the nutrition, public health and dentistry. The fluoride may be supplied to the human by sources other than water, also there is a variety in the amount of the fluoride consumed by different persons.

Key words : drinking water / fluoride concentration .

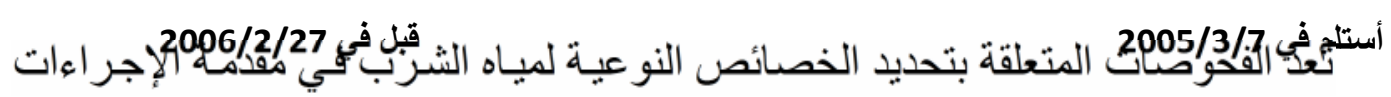

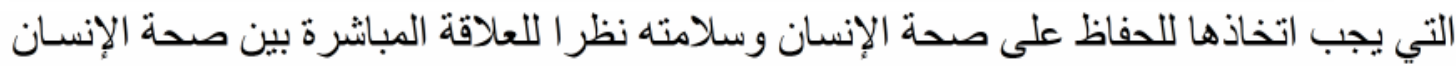

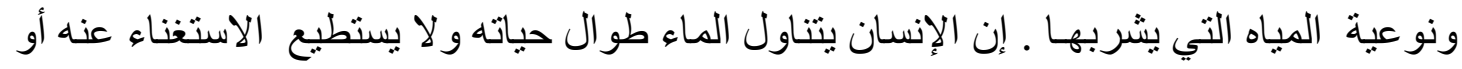

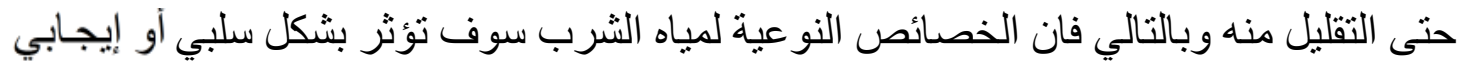

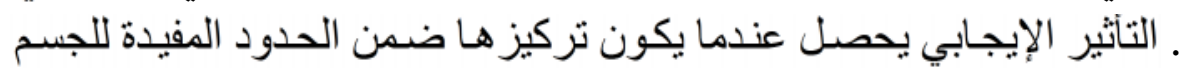

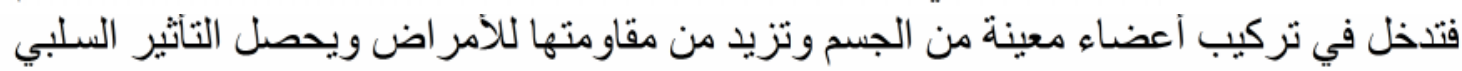

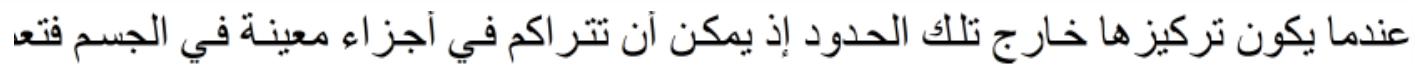

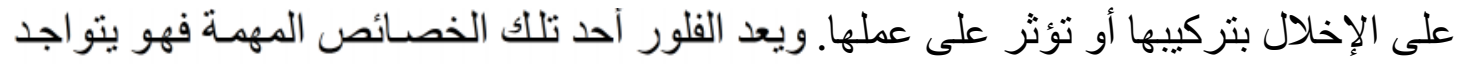

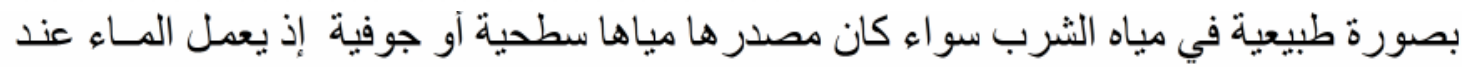

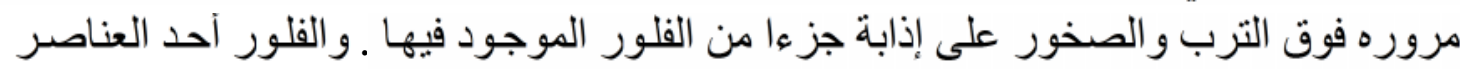

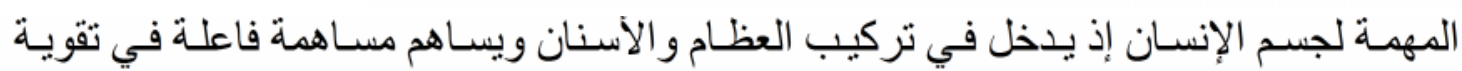

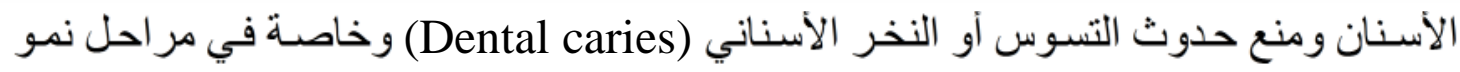

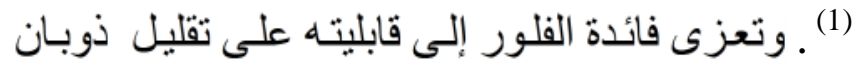

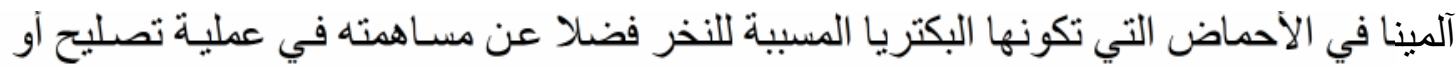

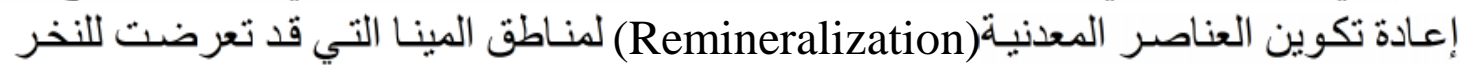
ويؤثر سلبيا على عمل هذه البكتريا (2) 


\section{تأثير تراكيز الفلور فى مياه الثرب على صحة الإنسان:}

ينت دراسـات عديدة ارتباط صحة الأسنان بتركيز الفلور في مياه الثرب فقد أظهرت

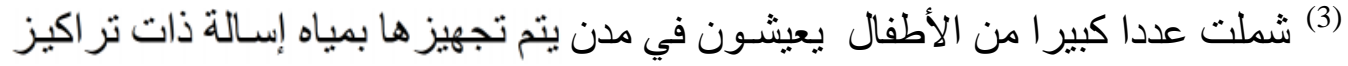

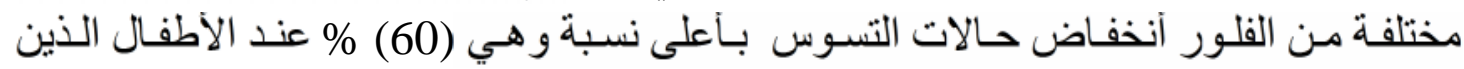

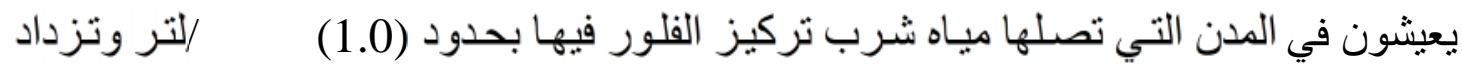

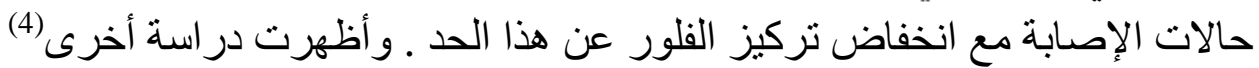

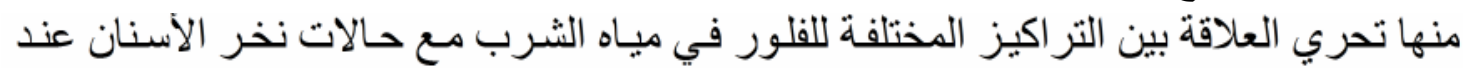

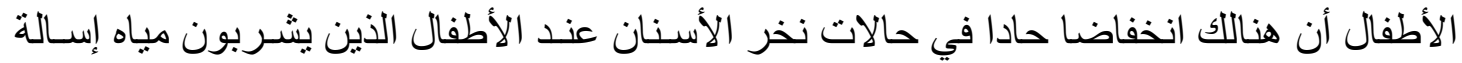

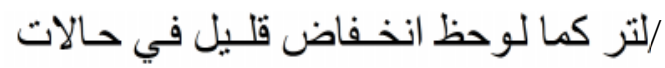

يتر اوح تركيز الفلور فيها بين (0.0)

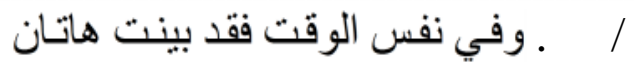

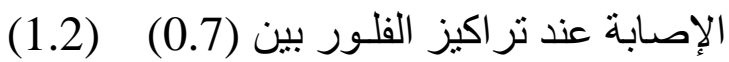

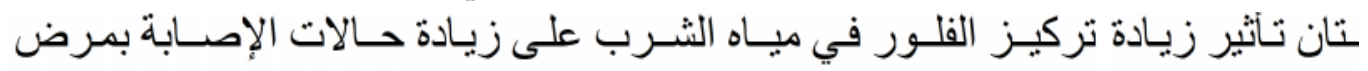

(Dental flourosis) التبقع الاسـناني(Dental mottling)

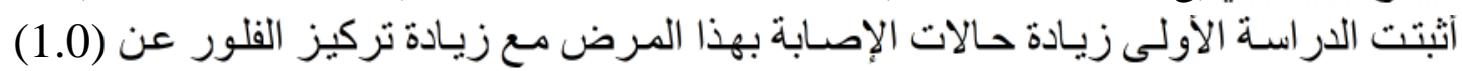

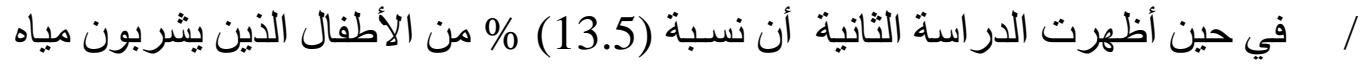

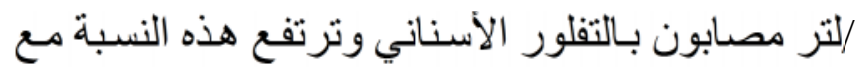

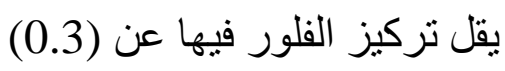

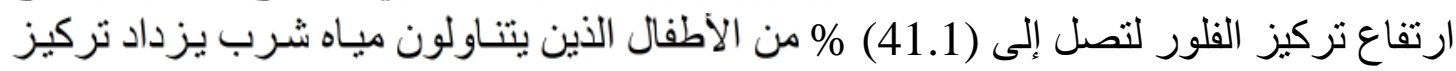

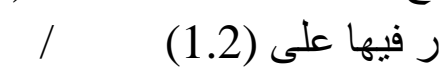

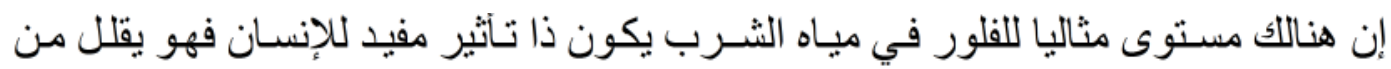

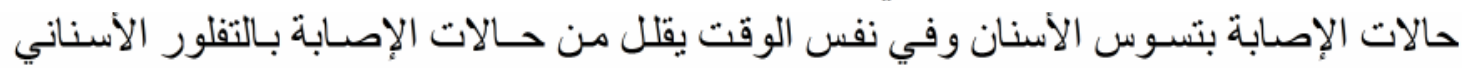

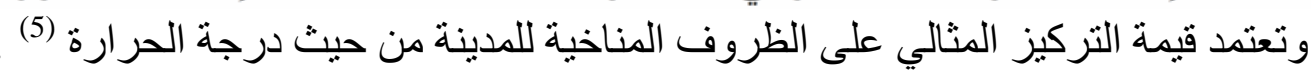

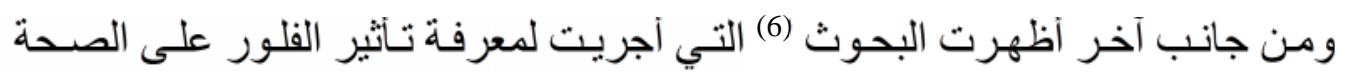

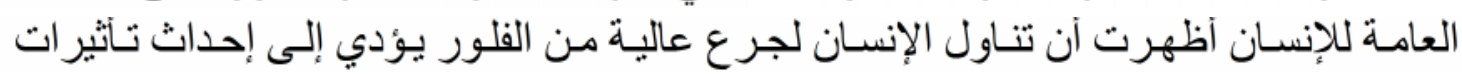

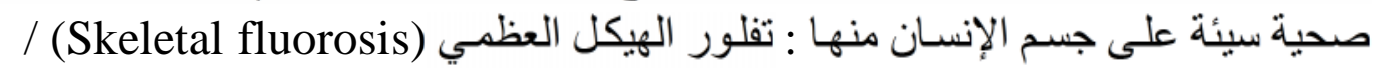
/(Thyroid gland) / خفض فاعلية الغدة الدرقية (Bone fracture) / التأثير على النسل (Children intelligence )

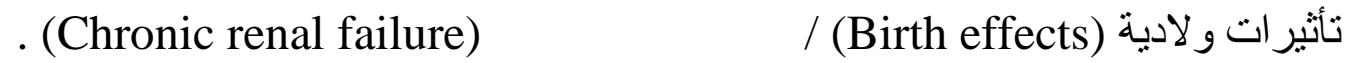

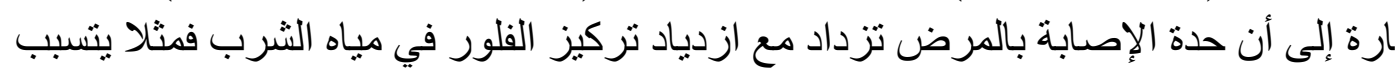

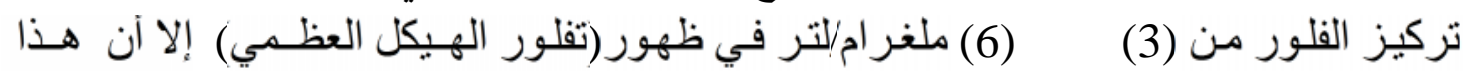

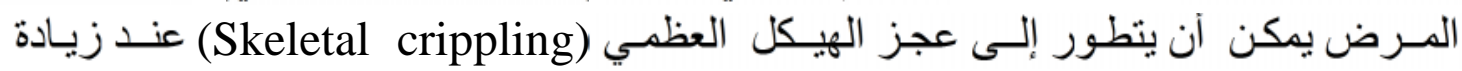
. ${ }^{(7)} /$ (10) تركيز

1 ـ التعريف بتر اكيز الفلور في مياه الثــرب داخل مدينة الموصل وبعض النواحي والآقضية 
2 - تحديد التركيز المثالي للفلور في مياه الثرب لمدينة الموصل . 3 - تقييم التراكيز التي جرى قياسها ومقارنتها مع التركيز المثالي ومع المعايير المحلية والعالمية

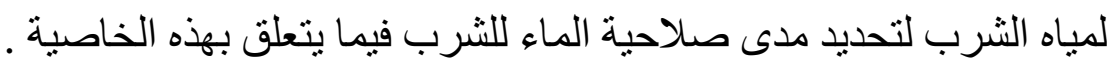
4 - مناقثشة طرق معالجة زيادة أو نقص الفلور ( ) .

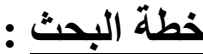

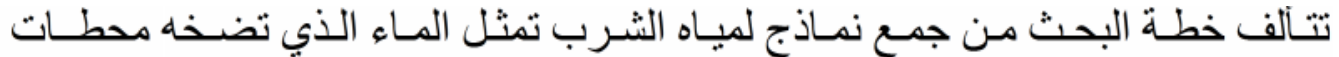

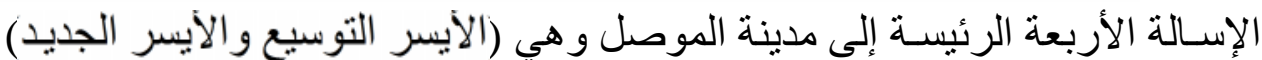

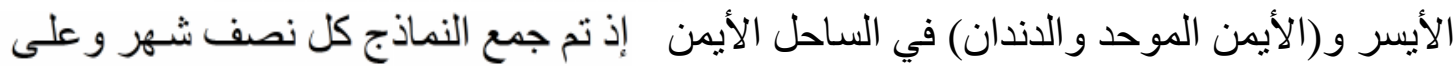

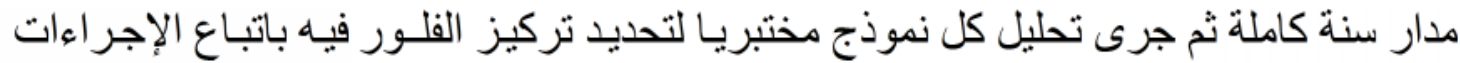

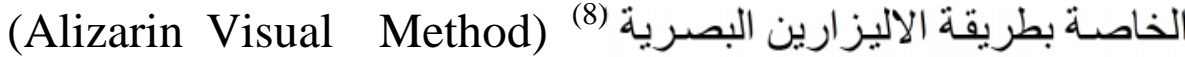

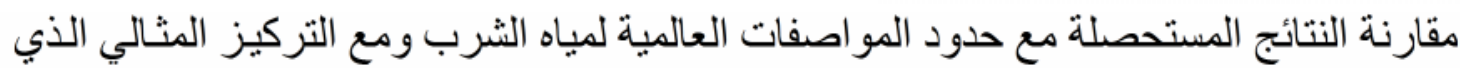

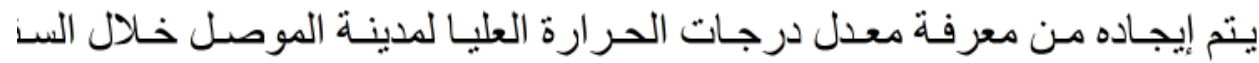

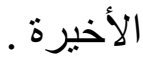

\section{النتائج والمناقشة :}

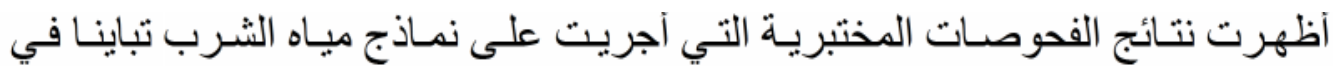

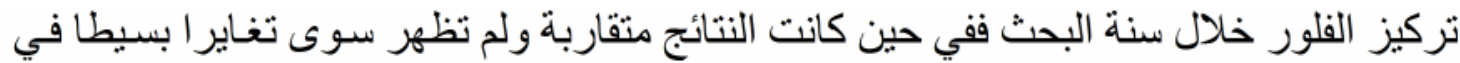

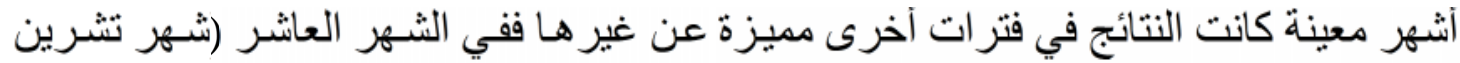

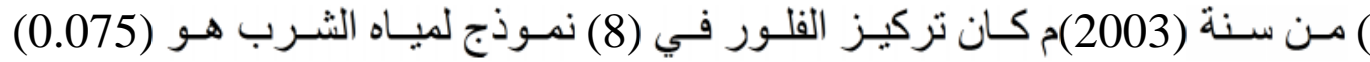

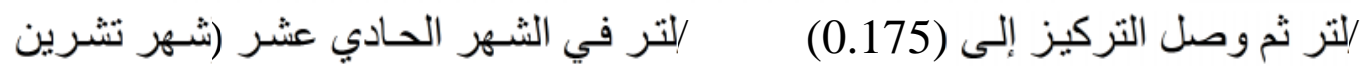

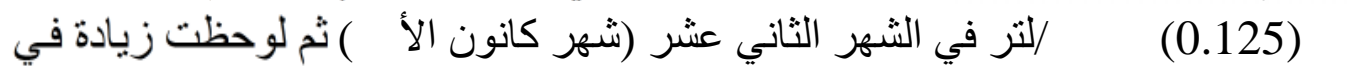
تركيز الفلور في نهايـة الثـهر الأول وبدايـة الثـهـر الثاني من عـام (2004) الثتر ثم بلغ أعلى قيمة له في نهايـة الثـهر الثاني وبداية الثـهر الثالث فقد أصبح الثركيز

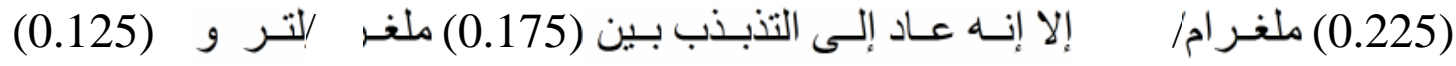

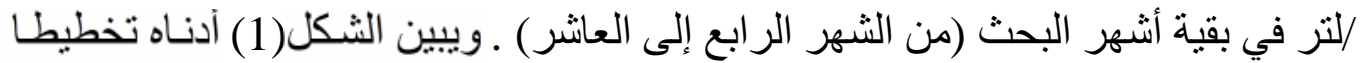

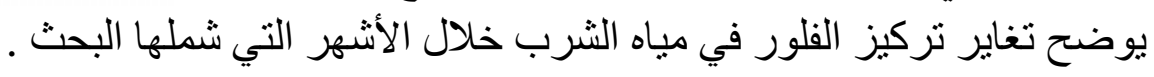

ويبين الثكل (2) مخططا يوضح نسب توزيع تر اكيز الفلور المقاسـة خـلال سـنة البحث

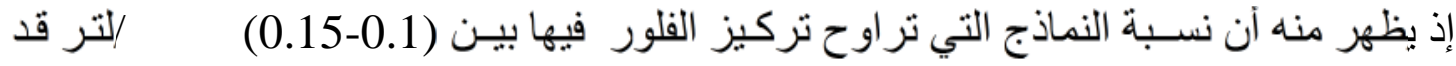
(54.166) \% في حين تراوح تركيز الفلور في (0)

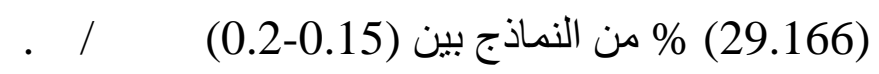




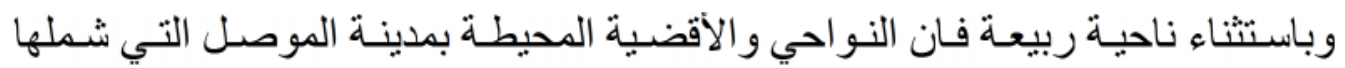

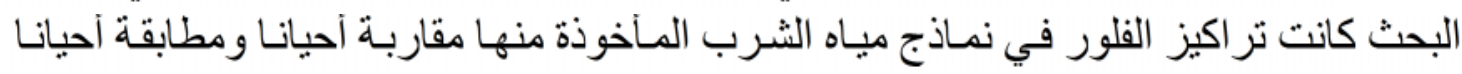

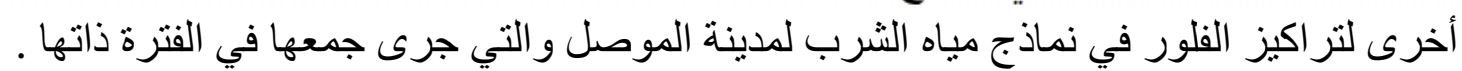

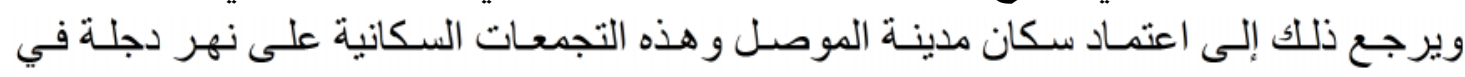

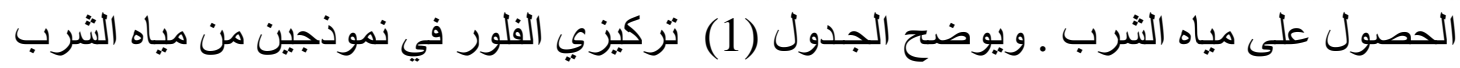
تم أخذهـا من كل ناحية أو قضــاء خلبال

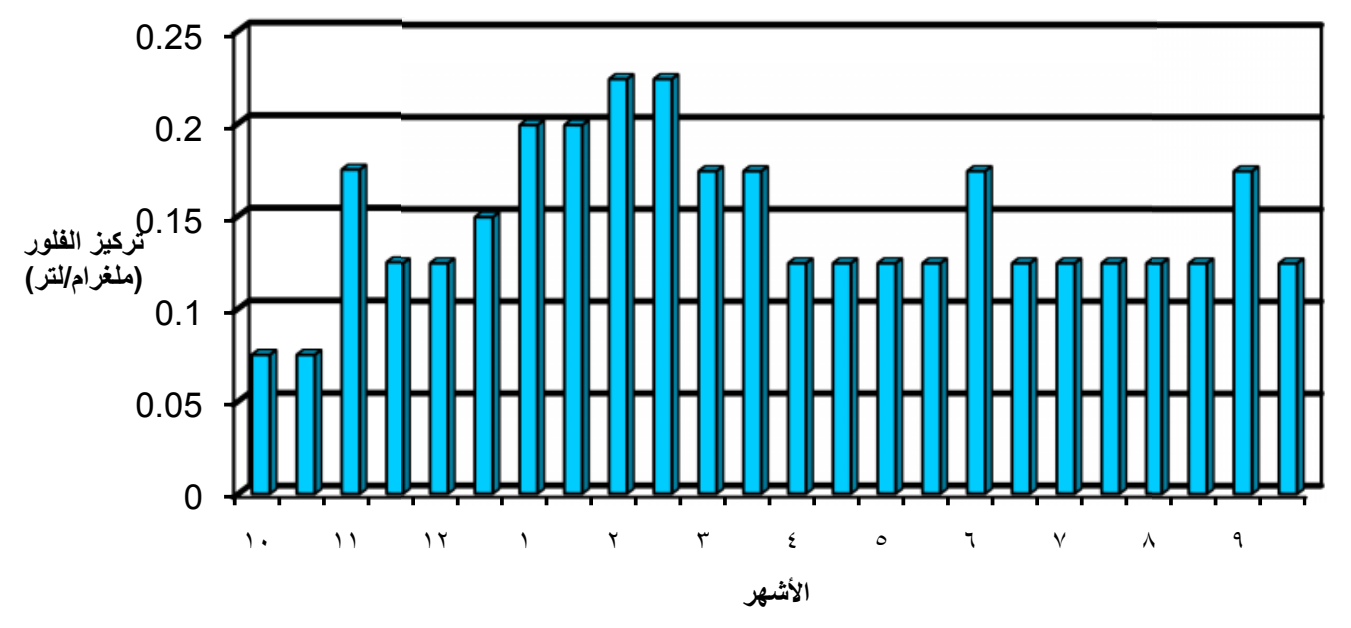

شكل رقم (1 ) تغاير تركيز الفلور خلال سنة البحث

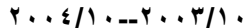




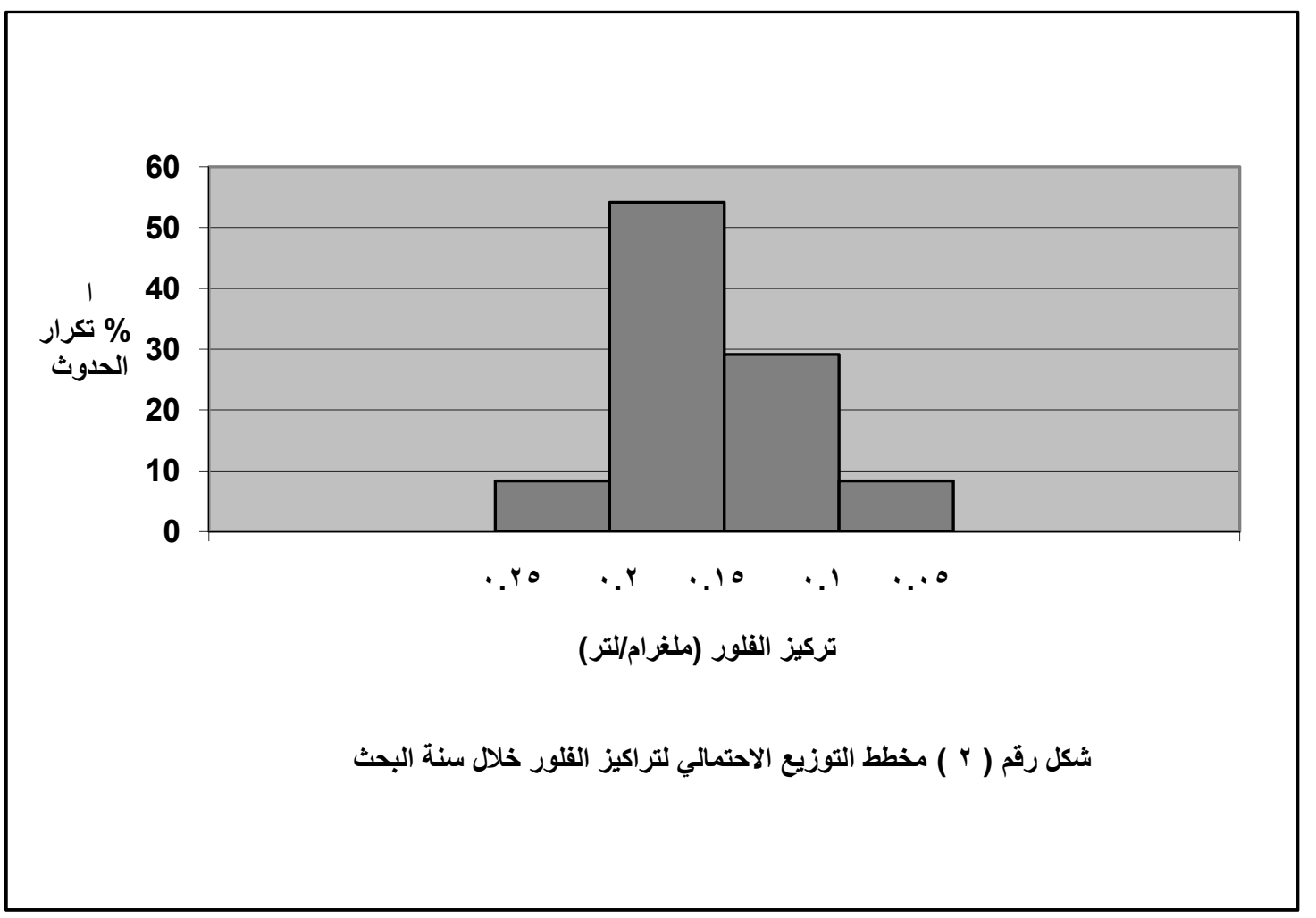

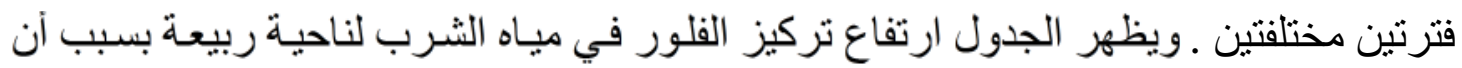

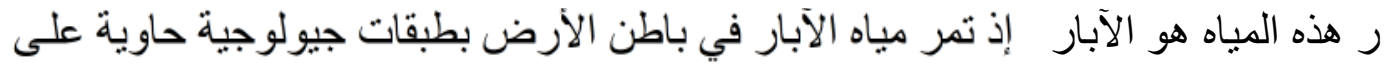

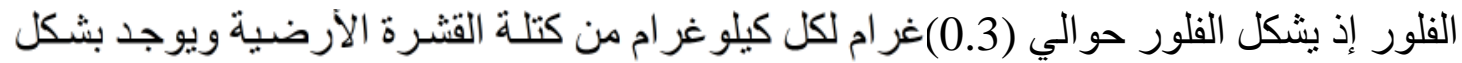

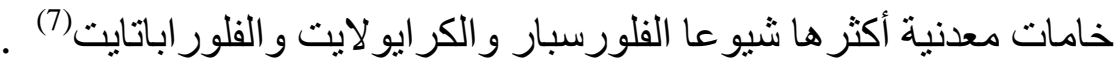

(1) : يز الفلور في مباه الثرب لبعض الأقضية و النواحي .

\begin{tabular}{|c|c|c|}
\hline \multicolumn{2}{|c|}{ تركيز الفلور ( } & القضاء أو الناحية \\
\hline (2) & (1) & \\
\hline 0.125 & 0.075 & \\
\hline 0.125 & 0.125 & بعثيقة \\
\hline 0.125 & 0.125 & الحمدانية \\
\hline 0.125 & 0.075 & \\
\hline 0.175 & 0.075 & \\
\hline 0.125 & 0.075 & \\
\hline
\end{tabular}




\begin{tabular}{||c|c|c||}
\hline 0.125 & 0.075 & تلكيف| \\
\hline 0.775 & 0.875 & ربي \\
\hline
\end{tabular}

إيجاد التركيز المثالي للفلور :

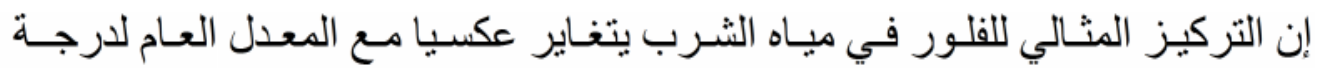

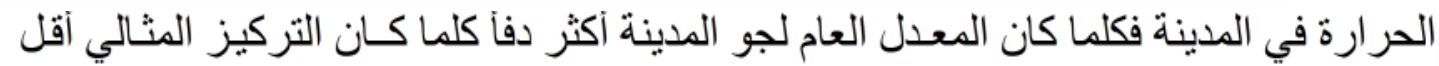

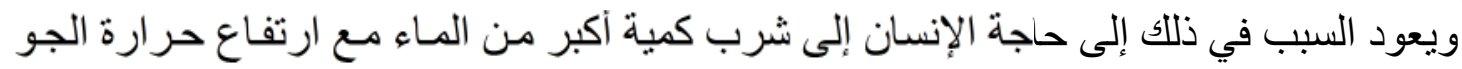

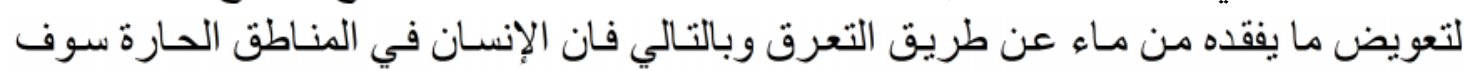

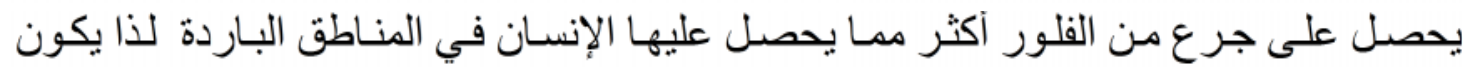

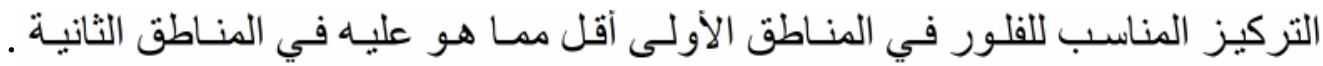

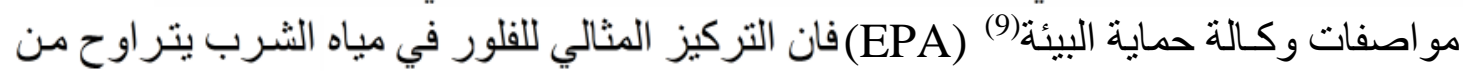

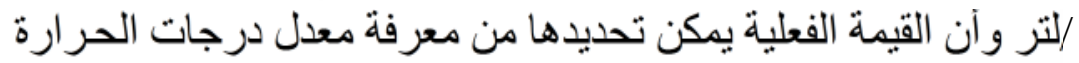

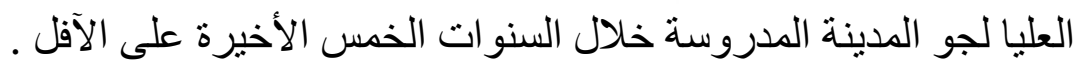

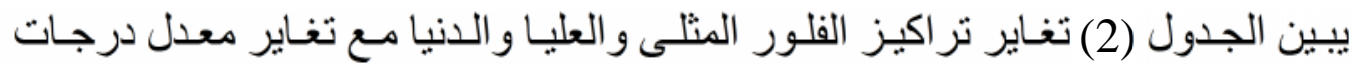

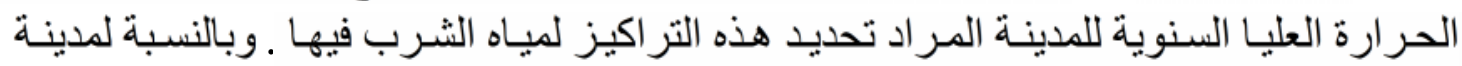

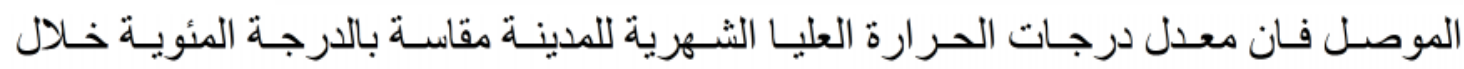

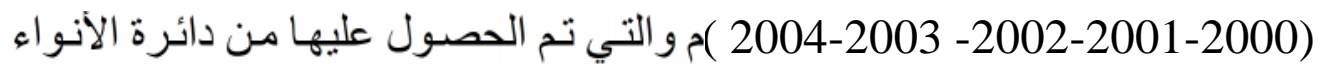

$$
\text { الجوية في المدينة موضحة في الجدول(3) . }
$$

(2) : تر اكيز الفلور الدنيا والعليا والمثالية لمياه الثرب الموافقة للمعدل السنوي للدرجات

العليا حسب وكالة حماية البيئة(9) - (9)

\begin{tabular}{|c|c|c|c|}
\hline$(1$ & \multicolumn{2}{|c|}{ تركيز أيون الفلور ( } & \multirow{2}{*}{ 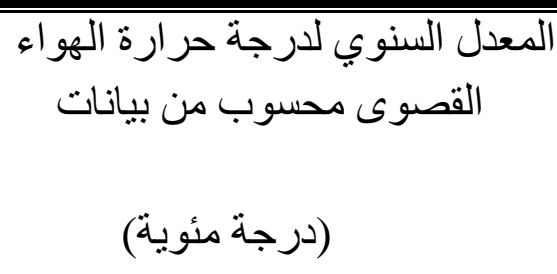 } \\
\hline العليا & المثالية & الدنبا & \\
\hline 1.7 & 1.2 & 0.9 & $12.05-10$ \\
\hline 1.5 & 1.1 & 0.8 & $14.61-12.11$ \\
\hline 1.3 & 1.0 & 0.8 & $17.66-14.66$ \\
\hline
\end{tabular}




\begin{tabular}{|c|c|c|c|}
\hline 1.2 & 0.9 & 0.7 & $21.44-17.72$ \\
\hline 1.0 & 0.8 & 0.7 & $26.22-21.5$ \\
\hline 0.8 & 0.7 & 0.6 & $32.5-2627$ \\
\hline
\end{tabular}

(3):المعدل الثهري للرجة الحر ارة المئويـة العليـا لمدينة الموصل خـلال الخمس سنوات

الأخيرة

\begin{tabular}{|c|c|c|c|c|c|c|c|c|c|c|c|c|}
\hline 12 & 11 & 10 & 9 & 8 & 7 & 6 & 5 & 4 & 3 & 2 & 1 & الثهر \\
\hline $\begin{array}{c}13 . \\
9\end{array}$ & $\begin{array}{c}22 . \\
2\end{array}$ & $\begin{array}{c}29 . \\
4\end{array}$ & $\begin{array}{c}38 . \\
2\end{array}$ & $\begin{array}{c}43 . \\
6\end{array}$ & $\begin{array}{c}46 . \\
4\end{array}$ & $\begin{array}{c}40 . \\
5\end{array}$ & $\begin{array}{c}34 . \\
1\end{array}$ & \begin{tabular}{|c}
28. \\
5
\end{tabular} & $\begin{array}{c}19 . \\
3\end{array}$ & $\begin{array}{c}15 \\
2\end{array}$ & 12 & 2000 \\
\hline $\begin{array}{c}15 . \\
2\end{array}$ & $\begin{array}{c}20 . \\
6\end{array}$ & $\begin{array}{c}31 . \\
4\end{array}$ & $\begin{array}{c}39 . \\
2\end{array}$ & 44 & $\begin{array}{c}44 . \\
1\end{array}$ & $\begin{array}{c}40 . \\
6\end{array}$ & $\begin{array}{c}32 . \\
3\end{array}$ & $\begin{array}{c}26 . \\
2\end{array}$ & $\begin{array}{c}22 . \\
2\end{array}$ & $\begin{array}{c}15 . \\
8\end{array}$ & $\begin{array}{c}14 . \\
1\end{array}$ & 2001 \\
\hline $\begin{array}{c}12 . \\
1\end{array}$ & $\begin{array}{c}24 . \\
1\end{array}$ & 32 & $\begin{array}{c}38 . \\
5\end{array}$ & $\begin{array}{c}41 . \\
6\end{array}$ & $\begin{array}{c}43 . \\
3\end{array}$ & $\begin{array}{c}39 . \\
2\end{array}$ & $\begin{array}{c}32 . \\
6\end{array}$ & $\begin{array}{c}22 . \\
9\end{array}$ & $\begin{array}{c}21 . \\
9\end{array}$ & $\begin{array}{c}17 . \\
5\end{array}$ & $\begin{array}{c}12 . \\
1\end{array}$ & 2002 \\
\hline $\begin{array}{c}14 . \\
1\end{array}$ & $\begin{array}{c}21 . \\
2\end{array}$ & $\begin{array}{c}32 . \\
33\end{array}$ & $\begin{array}{c}37 . \\
9\end{array}$ & \begin{tabular}{|c|}
44. \\
3
\end{tabular} & $\begin{array}{c}43 . \\
3\end{array}$ & $\begin{array}{c}40 . \\
5\end{array}$ & $\begin{array}{c}34 . \\
7\end{array}$ & $\begin{array}{c}25 . \\
1\end{array}$ & $\begin{array}{c}17 . \\
1\end{array}$ & $\begin{array}{c}13 . \\
1\end{array}$ & $\begin{array}{c}14 . \\
6\end{array}$ & 2003 \\
\hline $\begin{array}{c}13 . \\
7\end{array}$ & $\begin{array}{c}18 . \\
8\end{array}$ & $\begin{array}{c}32 . \\
9\end{array}$ & $\begin{array}{c}39 . \\
7\end{array}$ & $\begin{array}{c}42 . \\
3\end{array}$ & $\begin{array}{c}45 . \\
1\end{array}$ & $\begin{array}{c}39 . \\
7\end{array}$ & $\begin{array}{c}32 . \\
5\end{array}$ & $\begin{array}{c}25 . \\
8\end{array}$ & $\begin{array}{c}22 . \\
5\end{array}$ & $\begin{array}{c}14 . \\
2\end{array}$ & $\begin{array}{c}13 . \\
5\end{array}$ & 2004 \\
\hline
\end{tabular}

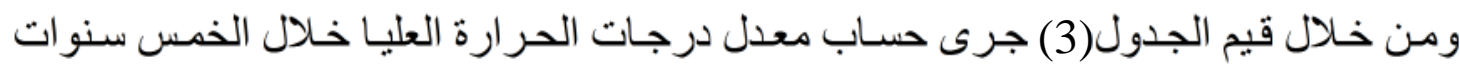

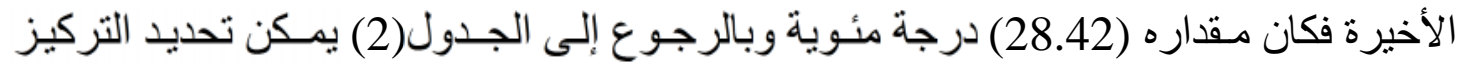

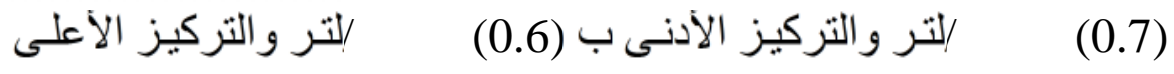

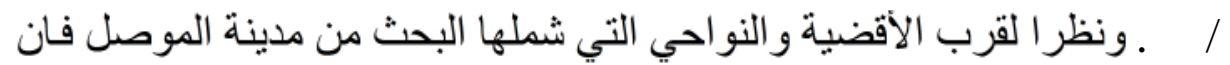

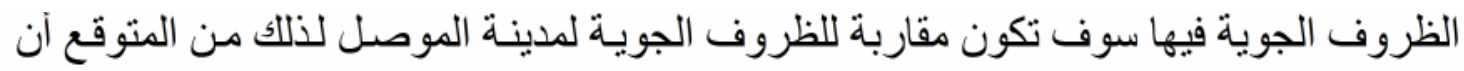

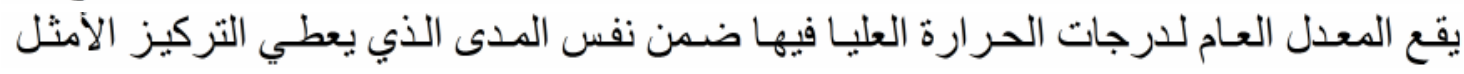

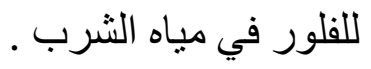




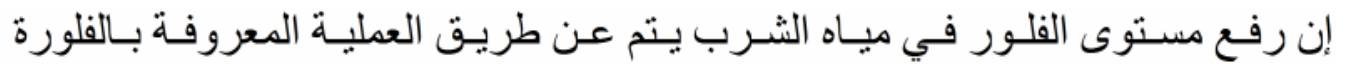

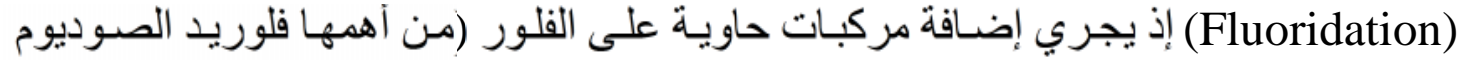

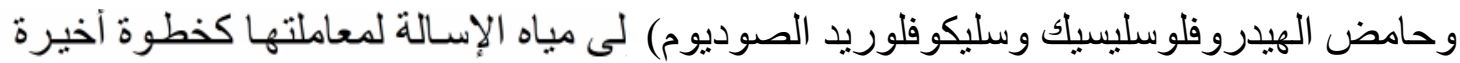

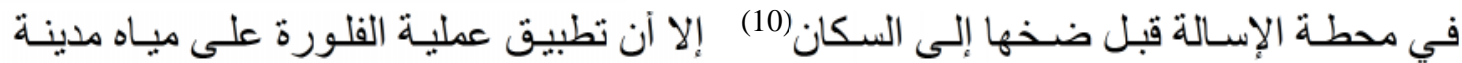

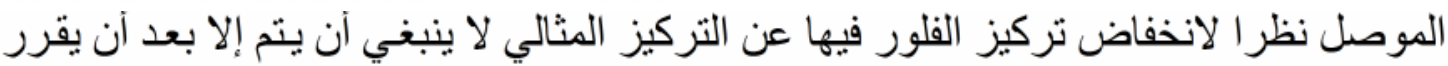

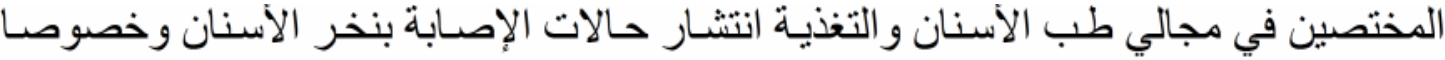

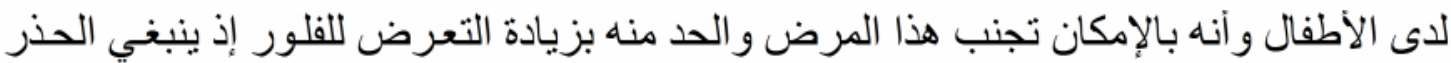
و عدم التسر ع في اتخاذ قرار إضافة الفلور الى مياه الثرب لرفئ لرفع تركيز الفلور فيه وذلك بسبب :

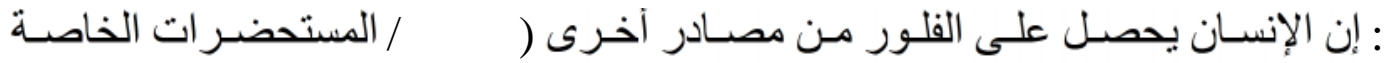

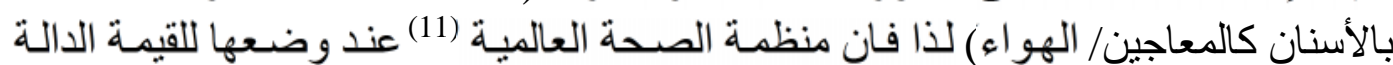

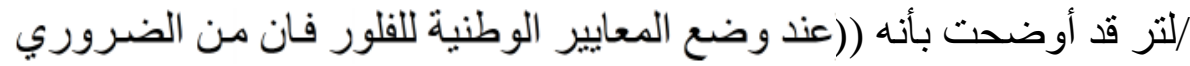

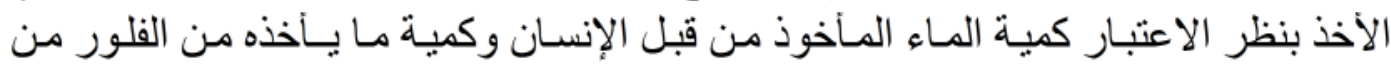

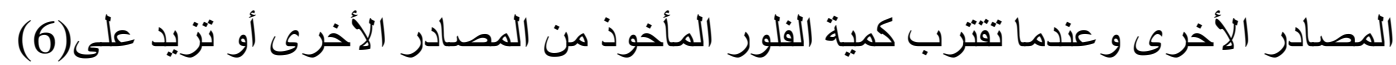

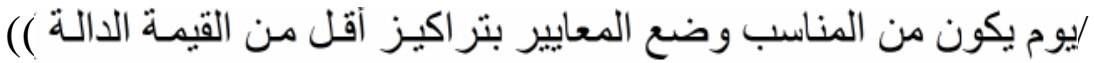

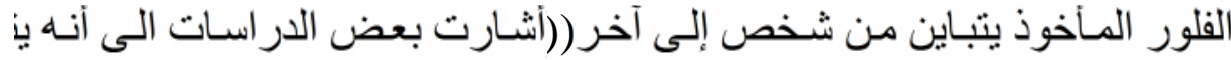

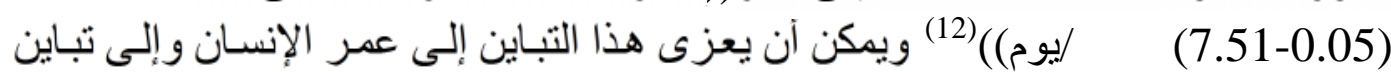

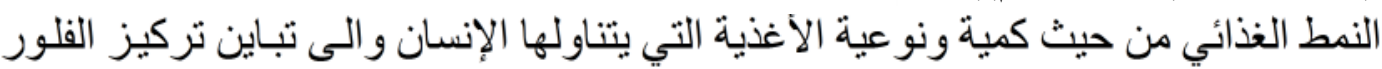

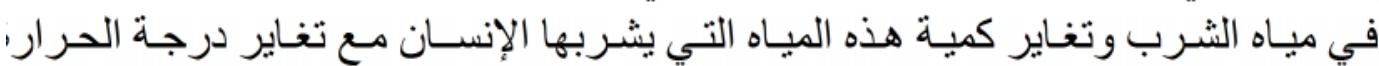

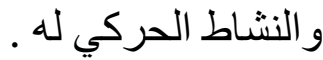

ثانيا : خطورة تعرض الإنسان إلى جرع زائدة من الفلور يمكن أن ينتج عنها آثار صحية سيئة

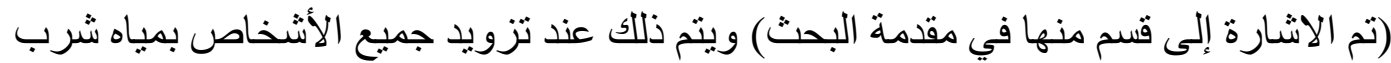

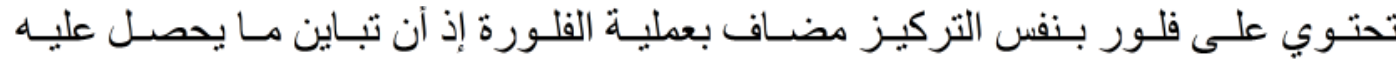

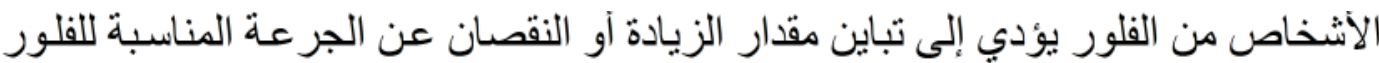

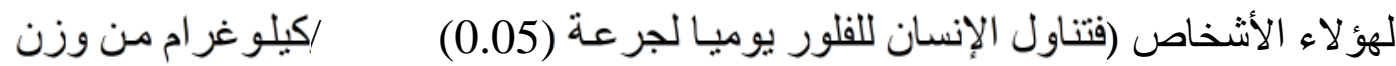

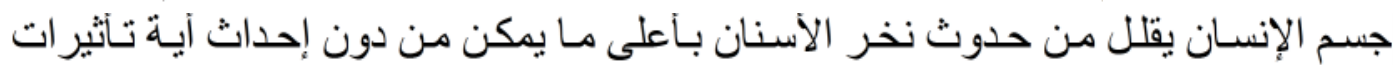

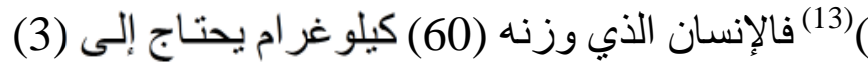
جانبية بما

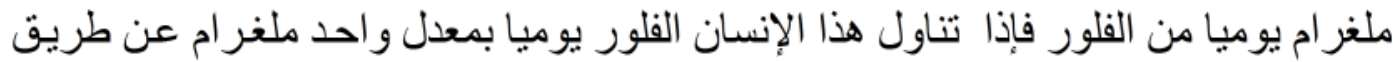

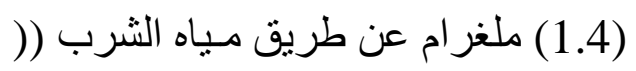

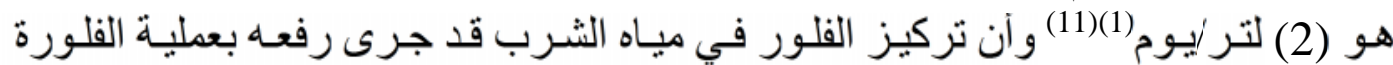

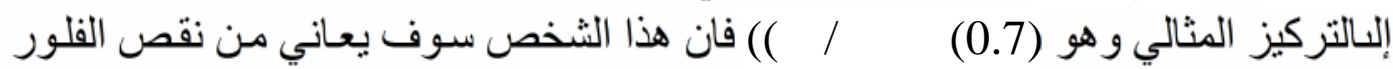

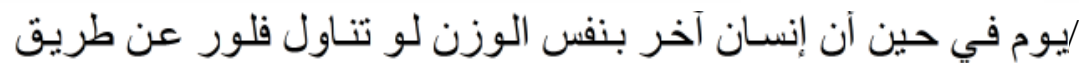

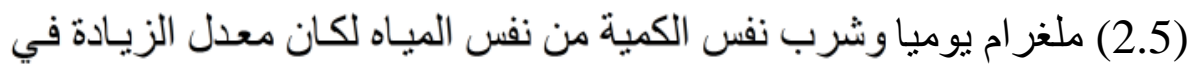

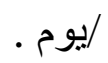

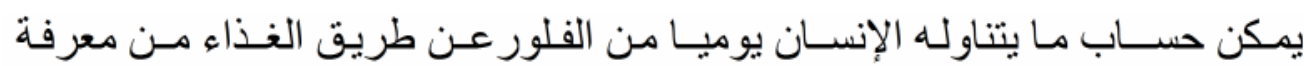

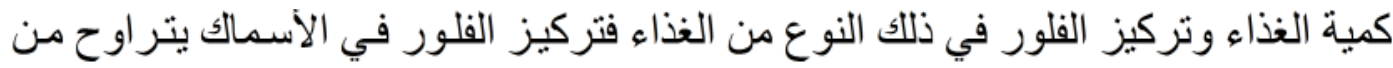

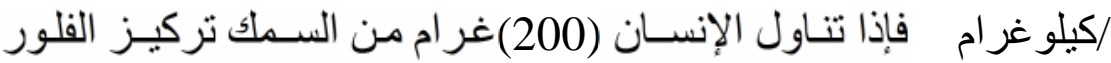




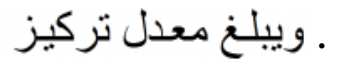

/كيلو غر ام فانه يكون قد تناول (2) (100)

فيه (10)

$$
\text { (3-2) }
$$

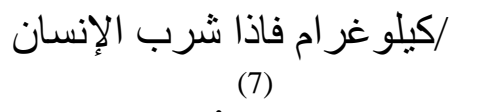

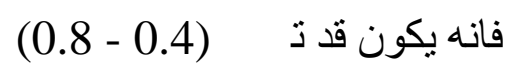

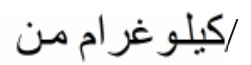

ويشار آيضا آن تناول الإنسان للفلور مرة واحدة بجرعة (3-7)

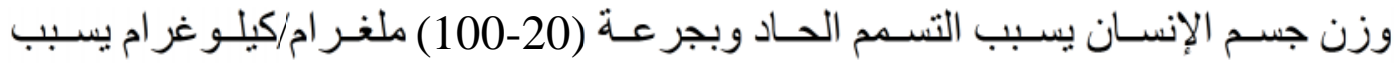

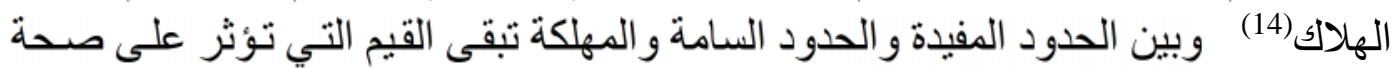

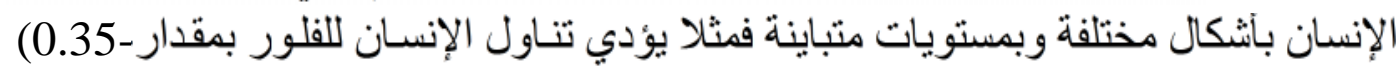

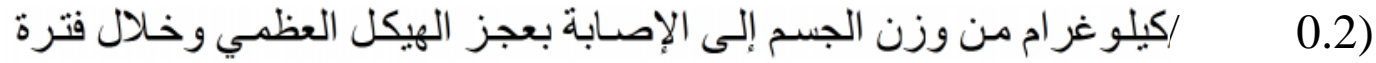

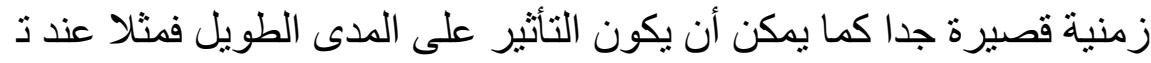

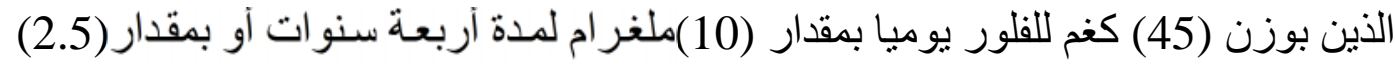

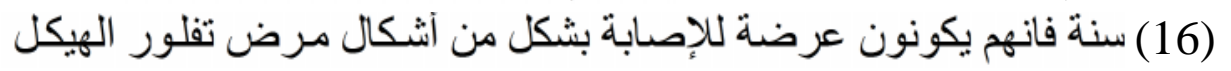

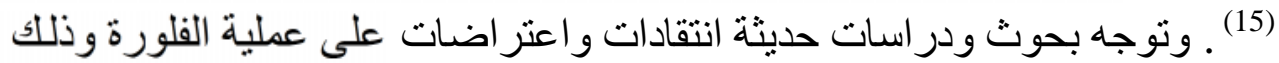
سباب صحية اقتصادية و أخلاقية(16)

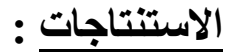

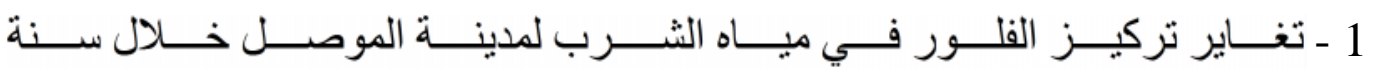

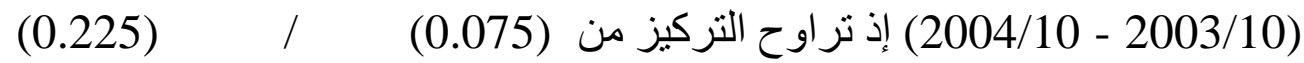

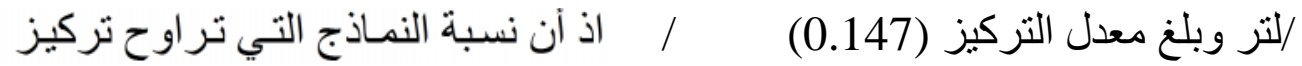

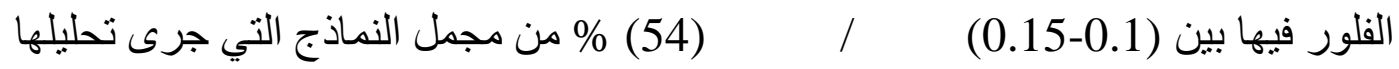

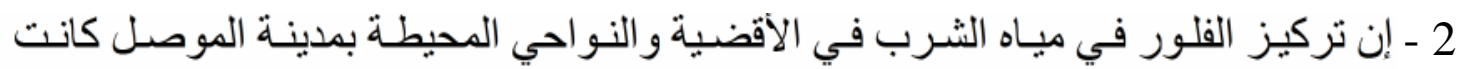

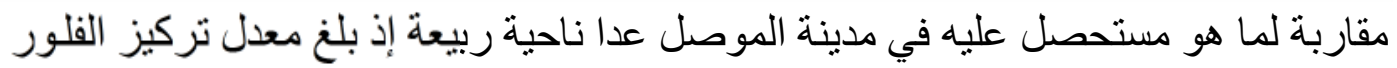

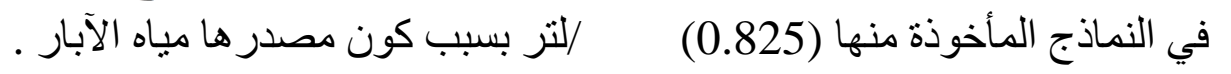
3- يتضـح من قيم تر اكيز الفلور التي جرى قياسـهـا لمياه الثـرب لمدينة الموصل و الاقضية

\section{المحيطة (باستثناء ناحية ربيعة ) بأنها :}

الحد الآقصى لتركيز الفلور الذي وضتعته دائرة حمايـة وتحسـين البيئـة العر اقيـة

(17) /

ـ أقل من التركيز المثالي المو افق للمعدل العام لجو المدينة حسب ال(EPA) . 
ـ أقل من أعلى تركيز مسـموح بـه للفلور حسـب ال(EPA) و الذي يمكن أن يـؤدي إلى

ـ أقل من القيمـة الـدالة (Guideline) التـي حددتها منظمة الصحة العالمية (11) وهي

$$
\begin{aligned}
& \text {. / (1.5) } \\
& \text { التزر وهو أعلى تركيز مسموح بـه للفلور في مياه الثرب وضتنه } \\
& \text { البيئية في كل من كندا وبريطانيا(18). }
\end{aligned}
$$

4ـ نظر الكون تركيز الفلور في مياه الثرب لمدينـة الموصل و المجمعات السكنية حولها التي التي

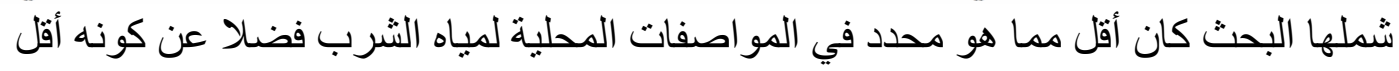

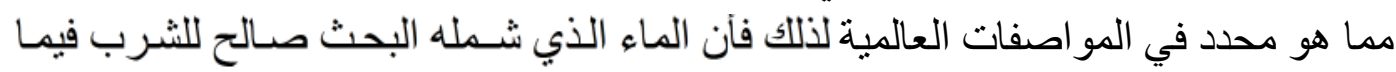

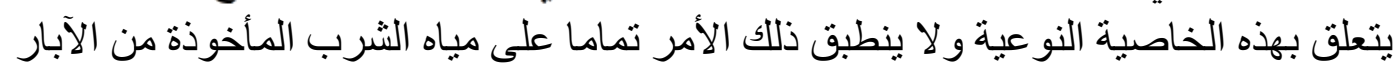
في ناحية ربيعة بسبب تجاوز معدل تركيز الفلور فيها القيمة المثالية والقيمة العليا المثبتة من الأبن

$$
\text { . (EPA) }
$$

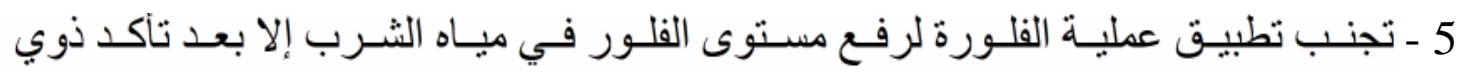

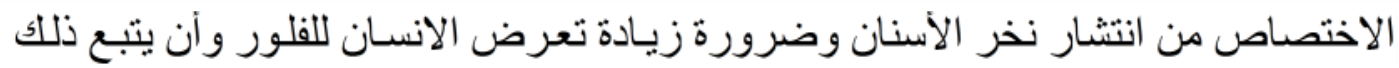

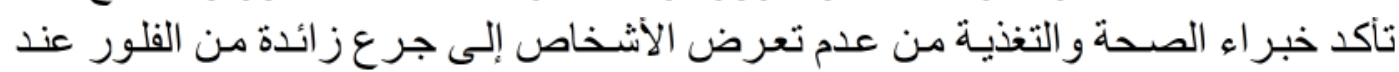

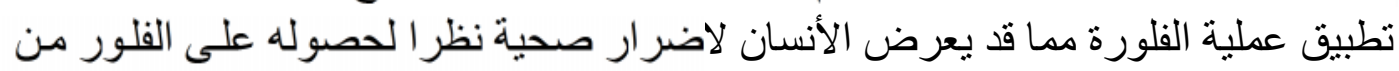

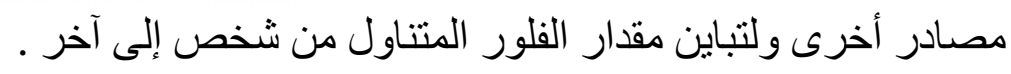

التوصيات :

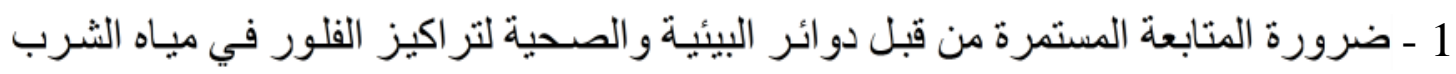

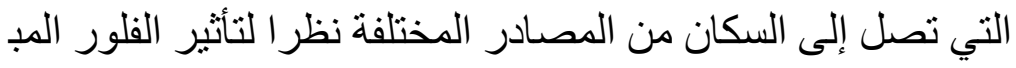

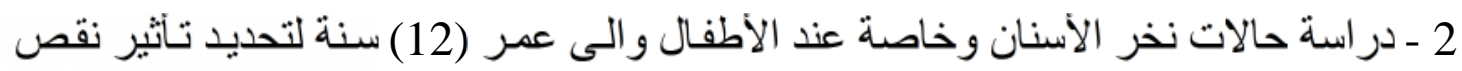

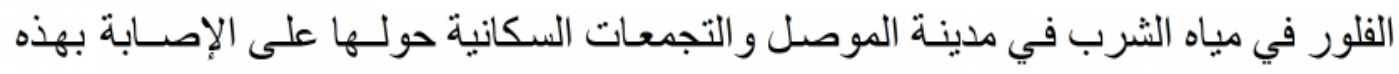

3 ـ دراسة حالات التفلور الأسناني في المناطق ذات التر اكيز العالية نسبيا من الفلور في مياه

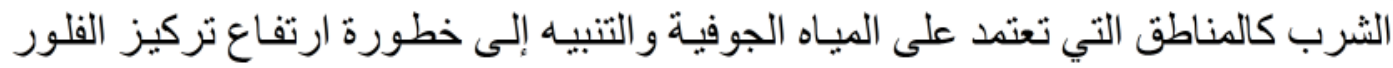

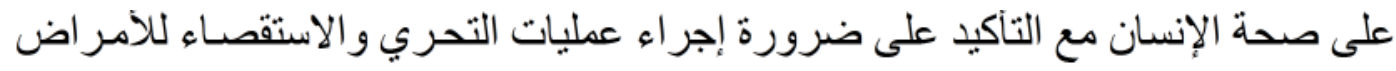
الناتجة من تعرض الإنسان لجرع عالية من الفلور و المنوقع حدوثها في هكن النح 
4 - عند اكتشاف مجمعات سكانية تحصل على مياه شرب ذات مستويات من الفلور آكثر مما هو

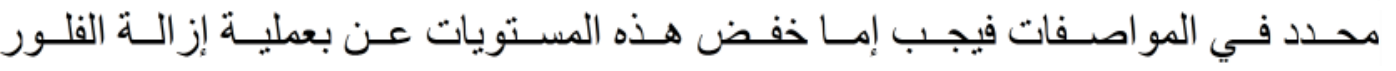
(Activated بامر ار المياه خلال وسط حبيبي من الالومينـا المنشطة فئهة (Defluoridation)

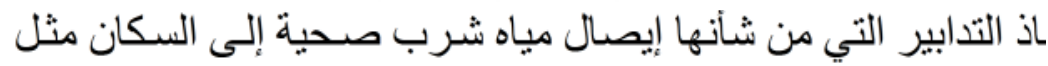
(9) Alumina) المياه المعبأة في القناني .

5 - توجيـه الأشـخاص الـذين يعـانون مـن نخـر الأسـنان بـالتطبيق الموضـعي Topical ) application)

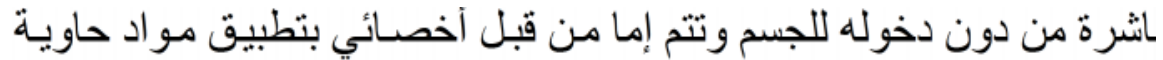

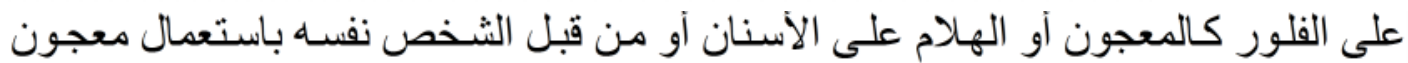
الأسنان أو غسول الفم الحاوية على الفلور (14)(19).

\section{المصادر :}

1- Lori A. Smolin and Mary B. Grosvenor, Nutrition Science and Applications, $4^{\text {th }}$ ed, John Wiley \& Sons, New York, , 2003.

2- Samaranayake L. P., Essential Microbiology for Dentistry, $2^{\text {nd }}$ ed, UK, Harcourt, 2002 .

3- American Water Works Association, Water Quality and Treatment, $3^{\text {rd }}$ ed, New York, Mc Graw-Hill Book Company,1971 .

4- Heller KE, Eklund SA and Burt BA, "Dental Caries and dental fluorosis at varying fluoride concentrations," J. Public Health Dent., 58(3):199, 1998 .

5- Mackenzie D. and David C., Introduction to Environmental Engineering, $2^{\text {nd }}$ ed, New York, Mc Graw-Hill Book Company,1991 .

6- Bibliography of Scientific Literature on Fluoride, From: www.slweb.org/

7-World Health Organization, Guidelines for drinking - water quality, vol. 2:

Health Criteria and other supporting information, $2^{\text {nd }}$ ed, Geneva,World Health

Organization, 1997 . 
8 - APHA, AWWA and WPCF, Standard Methods For the Examination of Water

and Wastewater, $16^{\text {th }}$ ed, American Public Health Association, Washington,

D.C., 1985 .

9- Viessman W. and Hammer M., Water Supply and Pollution Control, $4^{\text {th }}$ ed,

Harper and Row, New York, 1985.

10- Gerard K., Environmental Engineering, , Mc Graw - Hill Company, New

York, 1997.

11- World Health Organization, Guidelines for drinking - water quality, vol. 1,

Recommendations, 3th ed, World Health Organization, Geneva, 2004

12- World Health Organization, Environmental Health Criteria 227; Flourides,

World Health Organization, Geneva, 2002 .

13- Institute of Medicine, Food and nutrition Board, Dietary Reference Intakes

for Calcium, Phosphorus, Magnesium, VitaminD, and Fluoride. Washington,

D.C., National Academy Press, 1997 .

14- Bengt M. (editor), Goran K. and Sven P. (ass. editors), Pedodontics

A systematic Approach, , P.J. Schmidi, Copenhagen, 1981 .

15- Gary N. and Martin F., "The Fluoride Controversy Continues: An-Apdate- 
Part 1," J. Twonsend Letter for Doctors \& Patients, December, 2002. 16- Paul C., " The Absurdities of Water Fluoridation". From the Fluride Action

Network, at : www.fluorideaction.org/

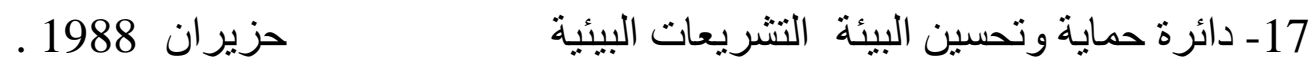

18- Alloway B., and Ayres, D., Chemical Principles of Environmental Pollution, $2^{\text {nd }}$, UK, Chapman \& Hall, 1997.

19- Murray J. (editor), The Prevention of Dental Disease, $2^{\text {nd }}$ ed,Oxford University

Press, New York 1989. 
